\title{
Improving Digital Marketing Strategy in Jordanian Air Aviation Sector for Becoming a Regional Training Center
}

\author{
Mahmud Agel Abu-Dalbouh ${ }^{1}$ \\ ${ }^{1}$ Irbid National University, Jordan \\ Correspondence: Mahmud Agel Abu-Dalbouh, Irbid National University, Jordan.
}

Received: April 20, 2020

doi:10.5539/ibr.v13n6p139

\author{
Accepted: May 20, 2020 \\ Online Published: May 25, 2020 \\ URL: https://doi.org/10.5539/ibr.v13n6p139
}

\begin{abstract}
The transformational processes of the global economy and the development of digital technologies necessitate a conceptual review of existing management strategies and their improvement, a change in the processes of obtaining knowledge and assessing their relationships. In modern conditions, to ensure the effectiveness of activities, the necessary element of management is the use of innovative information and digital technologies in business, which allow optimizing costs and optimizing financial results.

The expediency and relevance of the study, which is aimed at assessing the relationship of digital strategies and their impact on the Jordanian aviation sector, is substantiated. It has been taught that the availability of digital technologies contributes to the improvement of management strategies and educational processes, which allows them to become training centers at the regional level. It was determined that the development of digital tools (content, web pages, social networks, advertising, video and other marketing components) and their application in organization management strategies contribute to streamlining the management process and gaining knowledge. It is argued that the process of education and training of managers depends on the approach used by the organization's digital tools, as well as the type and industry of its economic activity. It is taught that the training used in the Jordanian aviation sector, as a managerial survey compiled by design specialists, explains the degree of accessibility of this sector of the economy and confirms the need to establish a training center at the regional level. It is proved that the establishment of a training center at the regional level will ensure the promotion of employees of the Jordanian aviation sector, state support, a new image and loyalty, which will make managers at the local and regional levels aware. To justify the relevance and necessity, a statistical one-way analysis of variance was carried out for the influence of factors on training processes in the aviation sector of Jordan.

The main results of statistical one-way analysis of variance interpret the importance of this study and the need to improve the digital strategy, and its application in marketing activities, which focus on 3digital. Unique practical recommendations have been developed that are based on customer focus and focus on three digital strategies (clients; educational product; digital tools), which will achieve the organization's strategic goals and positive financial results.
\end{abstract}

Keywords: digital strategy, air aviation, training center, e-customers, marketing, efficiency

\section{Introduction}

Throughout the existence of mankind, society has developed. It is well known that in its development it went through three stages: agrarian with a predominance of agriculture and manual labor, industrial with a dominance of industry and post-industrial. All developed countries have already passed into the third state, which is characterized by dominance in the economy of the service sector and the emergence of information technologies and computers, which entailed a significant simplification of the lives of people living in these countries. In other words, we began to live in a consumer society. However, the company does not stand still, its further development and the increasing dominance of the services sector over production have led to the fact that information technology and the IT sector have begun to play a key role in this movement, which greatly simplify the very mechanism by which a person receives any service. The advent of the Internet and the reduction in the cost of access to the global network have become a real information (digital) revolution that has changed our lives in general, and the economy in particular. 
The development of market relations is due to the high level of competition, which forces the management of organizations to review the management strategies used in order to maintain their competitive position in the world market. The transformation of management strategies in connection with the global globalization of markets and the development of new technologies allows us to change the management process and diversify production and approaches to its organization, and digital reassessment opens up new opportunities for the quality of services for their pricing, promotion and competitiveness. Modern business conditions lead to the fulfillment of mandatory conditions to ensure the effectiveness of activities and maximize results is the use of innovative technologies and management strategies. Particular attention should be paid to the development of digital organization management strategies, which dictate the conditions for ensuring specific positions and increasing the share of customer loyalty and their satisfaction with the organization's product / service. A digital strategy is a marketing plan whose goal is the general development and transformation of a business, the popularization of a product or brand. To achieve the objectives, research is conducted on the market, audience, competitors, their own competitive advantages are identified, suitable digital channels and specific tools are selected, and relevant technologies are used.

In modern science, there is no single approach and methodology for assessing the relationship of digital strategies, as well as their impact on the Jordanian aviation sector, which confirms the relevance and necessity of this study. The high level of competition in global markets, the transformation of existing mechanisms for managing organizations and the availability of digital technologies contribute to the continuous improvement of management strategies and necessitates the conceptual need for the establishment of training centers at the regional level, which should be examined in more detail and assessed by the level of significance of these factors based on the application statistical univariate analysis of variance tools.

The process of organizing the aviation sector of the Jordanian economy, which we are beginning to adapt to the new marketing environment in stages to solve new problems, focusing on marketing research, determining the needs of the market and consumers, the attitude of customers and their loyalty, analysis of strengths and weaknesses, as well as promotion, requires additional research. using digital tutorials. The intensive development of Internet technologies and their applications in the economy leads to positive results and economic benefits, which in the conditions of transformation of the world market is important and necessary to ensure specific positions.

\section{Literature Review}

There are many studies in the scientific literature that are aimed at the development of digital technologies in the economy, which are a driver of change and are reflected in studies (Chunch Heman \& Ken Burberry, 2013) that conceptualize the need to use innovative tools in the organization's management system to retain customers and market position. However, this approach does not allow to determine specific directions for improving the strategy, which will ensure not only the retention of customers and competitive positions in the market, but will increase these indicators, both in quantity and in qualitative measurement. It is worth noting a study (Dare Chaffey, 2017) that outlines the process of accelerating technologies and communications in business by creating a new approach and communication management strategy, which, unlike the existing ones, is aimed at improving interaction with key consumers, but does not allow comprehensive management of all the processes of the organization.

It should be noted that modern business conditions determine the need for the use in the activities of any organization of innovative information and digital technologies in the formation of strategic goals of organizations. In the scientific literature, there are several different views on the use of digital strategies of organizations. Digital strategy is a unique competitive advantage in electronic marketing all over the world. Digital marketing strategies are practically characterized by applications in the world of technologies for sustainable business activity (Sunil Gupta, 2018), using new digital opportunities. Current business conditions have led marketing managers to use many marketing communications forums as a digital strategy (Alexander Reason \& Damian Ryan, 2018). E-business firms are gaining sustainable competitive advantage through new digital strategies (Philip Kottler., 2017). The impact of training on the applied digital marketing strategy is mentioned in the study (Linda D., 2019), however, this approach does not reveal the main essence and mentions the main tools of digital marketing in building a strategy, which does not allow us to fully determine not only tool at assessment of their impact. It should be noted that not all the approaches presented consider the features of the influence of digital strategy on the learning process in the aviation sector of Jordan, which requires more in-depth research. 


\section{Research Problem and Research Methodology}

The theoretical and methodological basis of the study are the objective fundamental principles of the modern theory of digital marketing. In the research process, special methods of cognition were used: analysis and synthesis - to develop practical recommendations for improving the strategy of digital marketing in modern conditions; the graphical method and the method of constructing analytical tables - for visualizing the results of the study, statistical one-way analysis of variance - for assessing the impact of digital marketing factors on the learning process in the aviation sector of Jordan. The key data from the World Bank, the International Bank for Reconstruction and Development, and the International Monetary Fund, International Finance Corporation, Jordan Central Bank and selected banking institutions, academic us of domestic and foreign scientists, economists, marketers, etc.

The transformational processes of the global economy significantly affect the marketing system as a whole, including its containing elements, which each organization determines for itself based on strategic goals and initiatives. Since the intensive use of innovative tools and information technologies in business quickly finds its application, it is necessary to consider the features of the impact of digital marketing strategies on training the aviation sector of the Jordanian economy to form it at the regional level.

\section{Analysis of Data}

Features of training in the aviation sector of Jordan are related to perception, culture, propaganda around the learning process and the need to establish a training center at the regional level. The creation of the aviation sector of the Jordanian economy was in 1966, in parallel from the development of educational institutions and academies. It should be noted that the transport sector of the Jordanian economy is 2.1 billion dollars. US GDP, while participation in the aviation sector is 500 million JD. As for educational institutions, there are 5 of them in Jordan, in which there are multidirectional training programs, this sector occupies an example of 5\% of Jordan's gross domestic production and amounts to 42.2 million dollars. USA.

To create an overview of the state of knowledge and justify the need to assess the impact of training in the aviation sector on a digital marketing strategy to improve efficiency based on data (Civil Aviation Administration Annual Report - Jordan, 2017). A critical analysis of the literature in the framework of digital marketing research was carried out, the period from 2013-2018 was chosen as the start date of the analysis, this is due to the fact that the main digital marketing reviews from the analytical aspect and the interactive form of digital marketing communications are mainly activated during the specified time period.

\section{Discussion}

a) Features of the development of digital marketing in Jordan for the implementation of aviation training: social networks; content; webpage.

Transofmation of global markets requires continuous improvement of existing management methods of a modern organization. The process of making managerial and managerial decisions should ensure the effectiveness of the organization. A critical analysis of research in the field of digital marketing made it possible to substantiate that the development of digital technologies requires a conceptual review of existing management strategies and their improvement, changes in the processes of knowledge acquisition and assessment of their relationship. In modern conditions, to ensure the effectiveness of activities, a necessary control element is the use of innovative information and digital technologies in business, which allow optimizing costs and optimizing financial results. A methodology for assessing the relationship of digital strategies and their impact on the Jordanian aviation sector has been developed and proposed. It is taught that the availability of digital technologies helps to improve management strategies and educational processes, which allows them to become training centers at the regional level. It has been established that the development of digital tools (content, web pages, social networks, advertising, video and other marketing components) and their application in organization management strategies help optimize the management process and gain knowledge. The creation of a training center at the regional level will ensure the promotion of employees of the Jordanian aviation sector, state support, a new image and loyalty, which will inform leaders at the local and regional levels. Using the tools of statistical one-way analysis of variance, the influence of factors on educational processes in the aviation sector of Jordan was evaluated. The main results, of which interpret the importance of this study and the need to improve digital strategy and its application in 3digital-oriented marketing activities. Developed approaches and unique practical recommendations based on customer orientation and focused on three digital strategies (clients; educational product; digital tools) that will achieve the organization's strategic goals and positive financial results in modern business conditions. 
b) The main aspects of the development of digital strategies in Jordan: innovative tools and their impact on business processes

It should be noted that the development of the digital economy essentially connects the relationship between customers and organizations at the level of using innovative technologies that are based on a complex of digital marketing. The relevance of the digital community and its usefulness for understanding training in the Jordanian aviation sector has been investigated, and the client's role is to create a branding story that is dedicated to brand performance (Sonja Gensler, 2013). Studies of digital training strategies for the Jordanian aviation sector are being explored such as: content strategy (CS), Internet (WS), social networks (SM).The training process in the aviation sector of Jordan reflects good image-based aerial training in many areas, such as: safety training, a suitable environment, simulation, electronic advancement, new technologies, a good training plan, skills, experience. The main results of such training focus on many aspects, such as: cost, training hours, locations, technological equipment, promotion strategies to improve the aviation training sector to a regional training center (Civil Aviation Administration Annual Report - Jordan, 2018). It is worth noting that studies in the field of training in the aviation sector of the Jordanian economy allow us to understand the motivation of clients to create and disseminate an advertising campaign in order to reflect a positive understanding of the values of training in Jordan, and positive trainee clients create stories with brand names that affect the new brand for effective, sustainable air traffic education institutions. Digital marketing promotion in the aviation sector of the Jordanian economy depends on social interaction with the benefits of training courses, which reflect a positive image for customer satisfaction and increased loyalty. Consider the types of digital marketing strategies that have been recently used to create social networking sites and encourage customers to respond interactively (Daniel Rowels, 2017).

The results provide a way to build and stimulate a positive customer image about digital marketing strategies for training in aviation in Jordan, influence on the Internet and spreading a brand image to build loyalty for learning success, there are many digital promotion care strategies to attract customers and increase loyalty, in general, Jordan's aviation education policy is based on a US model, such as the Michigan Institute of Aviation and Technology, Aviation School and Wyotech. In Jordan, in the aviation sector of the economy, training is trying to become the best in the Middle East, having received an international certificate of training, high technology, safety, experience. Training should maximize quality, values, image, satisfaction and create intellectual knowledge in the field of aviation training, integrate solutions with information, improve a training-based information solution to help industry, there are many problems that specialists face because there are not enough funds, experience, specialized equipment, management, integrated training management, training needs analysis.

To improve the digital marketing strategy in the Jordanian aviation sector to become a regional training center, statistical tools of one-way analysis of variance should be used, which will assess the impact of the new strategy for each variable on the digital learning elements of the aviation sector. Analysis of variance is a method in mathematical statistics aimed at searching for dependences in experimental data by examining the significance of differences in average values. Unlike the t-test, it allows you to compare the average values of three or more groups. Developed by R. Fisher to analyze the results of experimental studies. The designation ANOVA is also found in the literature. To do this, we will carry out the following classification of strategies: content strategy, web page strategy, social media strategy. Cornbrash's alpha is 0.86 , which is explained by a high degree of suitability, stability and validity, which is presented in table 1.

Table 1. The main results of the analysis of variance assessment of the impact of digital marketing factors on the learning process in the aviation sector of Jordan

\begin{tabular}{lcc}
\hline Variables & N. Items & Alpha (a) \\
\hline Improve Digital Strategy (IDS) & 6 & 0.86 \\
Content (Co) & 7 & 0.89 \\
Web Pages (WP) & 5 & 0.81 \\
Social Media (SM) & 8 & 0.88 \\
\hline Standadi
\end{tabular}

Standard deviations are 3.81 and are presented in table 2 and reflect the degree of change in the effective indicator. 
Table 2. Standard deviations of the analysis of variance assessment of the impact of digital marketing factors on the learning process in the aviation sector of Jordan

\begin{tabular}{lccccc}
\hline & $\mathrm{N}$ & Minimum & Maximum & Mean & Std. Deviation \\
\hline Improve Digital Strategy (IDS) & 54 & 3.76 & 22.33 & 12.9291 & 3.81040 \\
Content (Co) & 54 & 3.33 & 23.44 & 13.8430 & 4.47073 \\
Web Pages (WP) & 54 & 3.65 & 24.00 & 14.5614 & 4.21659 \\
Social Media (SM) & 54 & 4.08 & 25.44 & 15.6342 & 3.99117 \\
Valid N (list wise) & 54 & $\mathrm{X}$ & $\mathrm{X}$ & $\mathrm{X}$ & $\mathrm{X}$ \\
\hline
\end{tabular}

The first standard deviation content strategy is 4.47 , the second web page strategy is 4.27 deviation, and the third social media strategy is 3.99 , which reflects the degree of information reliability. To interpret the main results of analysis of variance and assessment, the impact of the new strategy for each variable on the digital learning elements of the Jordanian aviation sector and the reflection of the significance of each variable, it is necessary to consider their collinearity, which is presented in Table 3.

Reflecting the training of the Jordanian aviation sector and explaining the influence of each variable by collinear tolerance, it is worth noting that the obtained economic-mathematical model is suitable and reflects the presence of 3 strategies for promoting training in Jordan, which provide an improvement in the new strategy, which is aimed at the benefits of training and communication support features digital technology.

Depending on the coefficient, the beta result becomes 0.066 , which means a change in the needs, desires, preferences of customers, after which it will have a positive effect on increasing the number of customers and enhancing their satisfaction and loyalty.

Table 3. Colinearity Statistics of the impact of digital marketing factors on the learning process in the aviation sector of Jordan

\begin{tabular}{lcc}
\hline Model & Tolerance & VIF \\
\hline Improve Digital Strategy (IDS) & 0.701 & 1.432 \\
Content (Co) & 0.689 & 1.654 \\
Web Pages (WP) & 0.703 & 1.452 \\
Social Media (SM) & 0.744 & 1.511 \\
\hline
\end{tabular}

The main parameters of the one-way dispersion model are presented in table 4 .

Table 4. The main parameters of the one-way dispersion model of the impact of digital marketing factors on the learning process in the aviation sector of Jordan

\begin{tabular}{ccccc}
\hline Model & R & R Square & Adjusted R Square & Std. Error of the Estimate \\
\hline 1 & $0.612(a)$ & 0.612 & 0.578 & 0.63455 \\
\hline
\end{tabular}

To conceptualize the main results of the study, it is worth interpreting the main results of analysis of variance, which are presented in table 5 .

Table 5. The main results dispersion analysis multicollenarity matrix of the impact of digital marketing factors on the learning process in the aviation sector of Jordan

\begin{tabular}{|c|c|c|c|c|c|}
\hline & & $\mathrm{Co}$ & PW & SM & IDS \\
\hline \multirow{3}{*}{ Co } & Pearson Correlation & 1 & $0.612(* *)$ & $0.639(* *)$ & $0.609(* *)$ \\
\hline & Sig. (2-tailed) & & 0.000 & 0.000 & 0.000 \\
\hline & $\mathrm{N}$ & 54 & 54 & 54 & 54 \\
\hline \multirow{3}{*}{ PW } & Pearson Correlation & $0.612(* *)$ & 1 & $0.597(* *)$ & $0.650(* *)$ \\
\hline & Sig. (2-tailed) & 000 & & 0.000 & 0.000 \\
\hline & $\mathrm{N}$ & 54 & 54 & 54 & 54 \\
\hline \multirow{3}{*}{ SM } & Pearson Correlation & $0.609(* *)$ & $0.650(* *)$ & $0.517(* *)$ & 1 \\
\hline & Sig. (2-tailed) & 0.000 & 0.000 & 0.000 & \\
\hline & $\mathrm{N}$ & 54 & 54 & 54 & 54 \\
\hline \multirow{3}{*}{ IDS } & Pearson Correlation & $0.643(* *)$ & $0.334(* *)$ & $0.328(* *)$ & $0.229(*)$ \\
\hline & Sig. (2-tailed) & 0.000 & 0.001 & 0.001 & 0.025 \\
\hline & $\mathrm{N}$ & 54 & 54 & 54 & 54 \\
\hline
\end{tabular}


To conceptualize this approach and determine key results, it is necessary to analyze the following hypotheses:

1) there is no statistically significant relationship $(\infty \leq 0.05)$ between digital strategy (content, web pages and social networks) and marketing of Jordan as a regional center for aviation training ;

2) there is no statistically significant relationship in $(\infty \leq 0.05)$ between the digital strategy (content) and marketing of Jordan as a regional center for aviation training;

$3)$ there is no statistically significant relationship in $(\infty \leq 0.05)$ between the digital strategy (web pages) and the marketing of Jordan as a regional center for aviation training.

There is no statistically significant relationship in $(\infty \leq 0.05)$ between digital strategy (social networks) and marketing of Jordan as a regional center for aviation training, as shown in Figure 1.

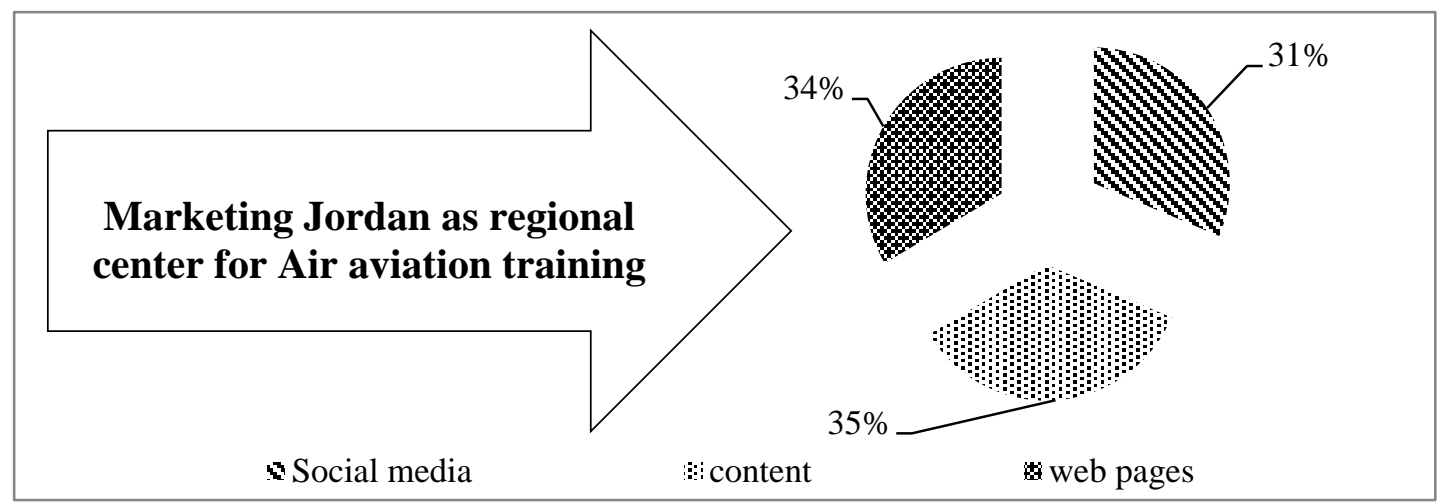

Figure 1. Conceptual aspects of digital marketing in Jordan as a regional center for training the aviation sector

The intensive development of the digital economy in the world and the introduction of innovative business tools determine their application and use in all sectors of the economy of developed countries. The development and use in practice of these tools and technologies provide all the necessary prerequisites for creating a new era of marketing - digital marketing.

\section{Conclusion}

In modern business conditions, to achieve all the strategically important goals of the organization, the necessary condition is the use of innovative management methods and tools. In order to achieve a competitive advantage, HR must adopt a new training strategy in the virtual world (digital) marketing strategy in Jordan, which depends on the following: 1) aspects of training diversification, understanding of market needs, applying a better strategy by focusing on the many shortcomings of these strategies and their improvement; 2) differentiation of content types, development of new pages, expansion of media applications, focus on e-advertising strategies $24 / 7 ; 3$ ) the use of innovative e-business tools aimed at training people in digital marketing; 4) the use of various electronic marketing tools, such as: television, media, social networks, content, web pages, focus on 3 digital strategies. It was taught that the availability of digital technology improves management strategies and learning processes, which allows them to become training centers at the regional level. The developed tools for analyzing the influence of factors on educational processes in the aviation sector of Jordan using statistical one-way analysis of variance can be applied in the practical activities of organizations. The results of the study are unique practical recommendations based on the methodological aspects of customer orientation and focused on three digital strategies (clients; educational product; digital tools) that will achieve the organization's strategic goals and positive financial results, taking into account all critical factors. It should be noted that achievement of all strategic goals and positive financial results, taking into account all critical factors that directly affect yanked on digital marketing strategies and the development of learning processes in Jordan atsiatsionnom sector. Significant in the process of organizing effective marketing and developing its digital tools are the central government bodies of Jordan, whose policies can intensively implement these technologies and their applications in the real business segment of the country.

\section{References}

Annual Report of Jordanian Civil Aviation authority 2016. Retrieved from https://www.icao.int/publications/journalsreports/2016/icao_training_report_vol8_No1.pdf 
Annual Report of Jordanian Civil Aviation authority 2017. Retrieved from https://www.icao.int/publications/journalsreports/2017/icao_training_report_vol8_No1.pdf

Annual Report of Jordanian Civil Aviation authority 2018. Retrieved from https://www.icao.int/publications/journalsreports/2018/icao_training_report_vol8_No1.pdf

Chunch, H., \& Ken, B. (2013). Digital Marketing Analytics, Marketing Sense of Consumer Data in Digital World (2nd ed.). Amazon digital services, pp. 382.

Daniel, R. (2017). Digital Branding, Complate Step By Step ,Guide to strategy, Tactics,Tools and Meaturment (2nd ed.). pp. 232.

Daniel, R., \& Chemas, B. (2018). Building Digital Culture, Category Winer, pp. 264.

Dare, C. (2017). Digital Business and E- commerce Management Strategy, implimentation and practice (6th ed.). pearson. Amazon digital services, pp. 182.

Ibn Haldun University. (2015). Air Transport Management, master degree. Turkish Air aviation Academy, 4(3), 29.

Jerry, W. V. M. (2015). Digital Marketing : Global Strategy, john willy sons inc. Amazon digital services, pp. 257.

Linda, D. H., \& Kieth, M. (2018). Digital Content Marketing, Global Strategy Role in Fostering Consumer Engagement. Amazon digital services, pp. 153.

Margrate, M. B. (2018). Generating Business Referrals Without Asking: A Simple Five Step Plan to a Referral Explosion. Morgan James Publishing, pp.122.

Mark, R., \& Graham, W. (2015). Digital To The Core: Remestaering Leader Ship For Your Industry, your Enterprise. Rout ledge, pp. 234.

Meshesha, B. (2018).Global Aviation Training. Build Your aviation Training Intellegence, International Civil Aviatin Organization, 1(2), 322.

Olivia, P. (2019). Digital Sensory Marketing :Integration New Technology Into Multisensory Online Experience. Amazon digital services, pp. 263.

Philip, K. (2017). Marketing 4.0 : Moving from Traditional to Digital, iwan setlwan led, Simon kingsnorth. Amazon digital services, pp. 200.

Sonja, G. (2013). Maniging Brand In The Social Media Envirnoment. Journal of interactive marketing, 27, 242-256. https://doi.org/10.1016/j.intmar.2013.09.004

Vankat, V. (2017). The Digital Matrix, New Rules For Business Transformation Through Technolog. Penguin books, pp. 224.

Zeng, F. (2009) Social Factors In User Perception and Response to Advertizing in Online Social Net Working Communities. Journal of interactive advertising, 10(1), 1-13. https://doi.org/10.1080/15252019.2009.10722159

Zhan, W., \& Hyun, G. (2017). Can Social Media Marketing Improve Customer Relation Ship. Journal of Interactive Marketing, 39(C), 15-26. https://doi.org/10.1016/j.intmar.2017.02.004

\section{Copyrights}

Copyright for this article is retained by the author(s), with first publication rights granted to the journal.

This is an open-access article distributed under the terms and conditions of the Creative Commons Attribution license (http://creativecommons.org/licenses/by/4.0/). 